\title{
Prices, profits and exchange rate uncertainty: The case of Bertrand competition in differentiated goods
}

\author{
Richard Friberg*† \\ Updated version of WP 196, \\ Stockholm School of Economics
}

January 30, 1998

\begin{abstract}
This paper studies a simple duopoly model of price competition under exchange rate uncertainty with pre-set prices and differentiated goods. Competitors come from different countries and compete in a foreign market. We study the effect of the price setting currency chosen on expected prices, profits and exchange rate exposure as well as equilibrium choice of price setting currency. For a wide range of parameter values price setting in the importer's currency is the dominant strategy. Implications of limited exchange rate pass-through for exchange rate exposure are discussed. The exchange rate pass-through elasticity is shown to be increasing in own-price effects. Parallels are drawn to the literature on strategic trade policy.

Keywords: pricing of exports, exchange rate pass-through, exchange rate exposure., JEL:F23
\end{abstract}

*I wish to thank Karl Jungenfelt, Carsten Kowalczyk, Anders Vredin and seminar participants at the Stockholm School of Economics, the Institute for International Economic Studies and EEA '97 for valuable comments. A special thank you to Rickard Eriksson for a careful reading. All remaining errors are mine. Financial support from Bankforskningsinstitutet is gratefully acknowledged.

${ }^{\dagger}$ Richard Friberg, Stockholm School of Economics, P.O. Box 6501, S-113 83 Stockholm, Sweden. Tel: +46-8-736 9645, fax:+46-31 32 07, e-mail: nerf@hhs.se 


\section{Introduction}

This paper studies exchange rate pass-through ${ }^{1}$, exposure ${ }^{2}$ and price setting currencies under exchange rate uncertainty. It is motivated by what we perceive as potentially important issues that have received little or no formal attention in the literature on exchange rate pass-through and exposure. How does the price setting currency of a firm's competitor affect the firm's exchange rate exposure? What are connections between exchange rate pass-through and exposure? What is the effect on an exporter's profits from an expected depreciation of its currency? Of an unexpected? What are the effects of market power on pass-through when there is competition?

The effects of exchange rate variability on prices and profits will be dependent on the market structure and the form of competition. Several authors have noted that Bertrand competition in differentiated goods is a form of competition that should be empirically relevant for issues of prices and exchange rates. ${ }^{3}$ In this paper we study Bertrand competition in differentiated goods with pre-set prices under exchange rate uncertainty. ${ }^{4}$ The assumption of price competition allows us to study issues of e.g. price setting currencies. This could for obvious reasons not be done if we model firms as setting quantity. We study a duopoly where firms are of different nationalities and compete in a single, foreign, market. ${ }^{5}$ Firms have to set price in one of three currencies (their own, that of

\footnotetext{
${ }^{1}$ How import prices of traded goods respond to exchange rate changes. See Menon (1995) for a survey.

${ }^{2}$ Exchange rate exposure is defined as the sensitivity of the value of a firm to exchange rate surprises, see e.g. Adler and Dumas (1984).

${ }^{3}$ Krugman (1987, p. 62) states about the study of exchange rates and prices "A more realistic model, then, would be one in which firms produce differentiated products and probably engage in Bertrand competition". Gottfries (1994), in an empirical study of Swedish export pricing, interprets his findings as supporting the view that (p.23-25) "A natural interpretation of the results is that prices are set a few quarters in advance...This supports the view that, in the short run, firms set prices rather than quantities. The mode of competition is Bertrand, and demand is very inelastic in the short run"

${ }^{4}$ The assumption of pre-set price should not be controversial - given that a floating exchange rate fluctuates literally by the minute it would be prohibitively expensive in many markets to reoptimize offer prices every time the exchange rate changes.

${ }^{5}$ By having a three country model we are able to discuss issues of price setting in a "third currency" and exchange
} 
the importer or a that of the competitor) under exchange rate uncertainty. After the exchange rate is known, the importer decides desired quantities at the prices that he faces.

There has been some study of quantity competition under exchange rate uncertainty, ${ }^{6}$ but we are only aware of one article that studies price competition under exchange rate uncertainty, Fischer $(1989){ }^{7}$ Fischer studies the case of Bertrand competition in homogenous goods in a two country model. In Fischer's framework each firm sets price in his own currency before the exchange rate is known. After the realization of exchange rates world demand is allocated. Firms' marginal costs are constant in their domestic currency and they face no capacity constraints. Fischer's focus is on how the number of competitors in the different markets affect exchange rate pass-through. He finds that foreign monopoly tends to decrease expected pass-through into import prices relative to what the case would be if there were several foreign firms. A foreign monopolist will increase profit margins, measured in his own currency, when the exchange rate is expected to move in a favorable direction for him.

In section 2 we develop our simple model with demand functions that are linear in price and marginal costs that are constant in each exporter's domestic currency. The functional forms are attractive as they yield manageable expressions and match the common empirical finding of less than full pass-through. ${ }^{8}$

Section 3 studies how the choice of price setting currency affects expected prices, expected profits and exchange rate exposure when there are no changes in the expected values of exchange rates. The analysis bears a strong connection to the analysis of choice of price setting currency for a residual demand monopolist found in e.g. Baron (1976) and Friberg (1998). ${ }^{9}$ Section 3.3 studies the

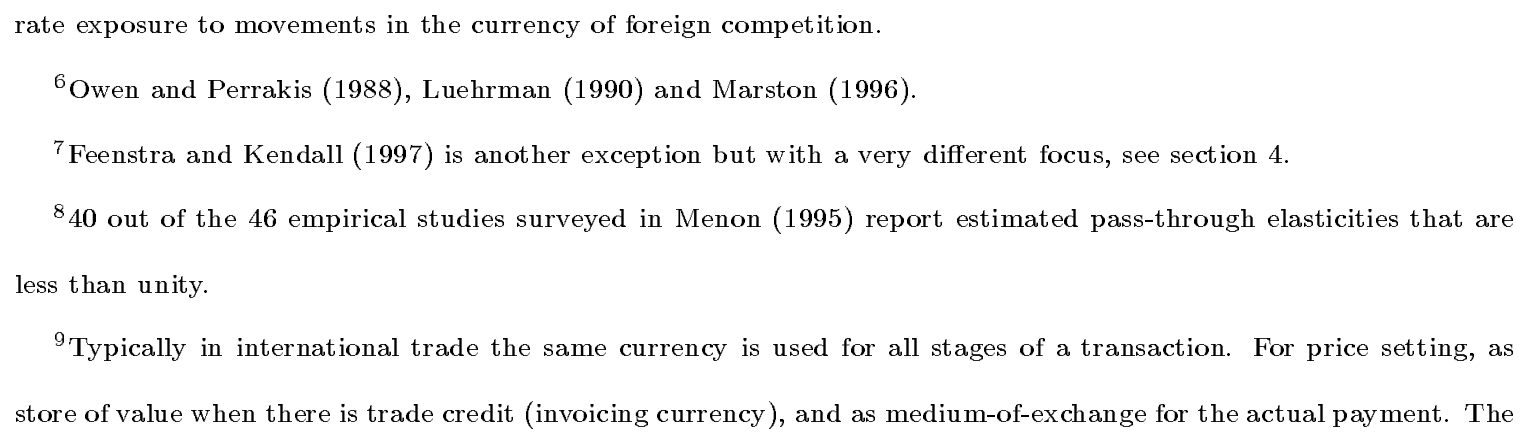

${ }^{9}$ Typically in international trade the same currency is used for all stages of a transaction. For price setting, as store of value when there is trade credit (invoicing currency), and as medium-of-exchange for the actual payment. The 
equilibrium choice of price setting currencies for the numerical cases that we study in section 3.1 and 3.2. Price setting in the importer's currency is the dominant strategy for both firms when cross-price effects are low. With higher cross-price effects there are no dominant strategies. However, the sole Nash equilibrium is for both firms to set price in the importer's currency (except for unreasonably strong cross-price effects, then there are three Nash equilibria, the three cases where both firms set price in the same currency). Section 3.4 studies the issue of exchange rate exposure. We note that when both firms set price in the importer's currency the exchange rate exposure is simply (certain) revenue in foreign currency.

In section 4 we focus on the effects of an expected exchange rate change (of one exporter's currency) on prices and profits. Exchange rate pass-through (in absolute value) is seen to depend positively on the market power - a firm that has more market power (lower own-price effect on demand) will pass-through more of an expected exchange rate change onto import prices. We also show that pass-through depends negatively on the variance of the exchange rate. The worse the quality of the signal (expected exchange rate change), the less will the exporter respond to it (less pass-through). The effect of market power and substitutability of goods on the pass-through elasticity, is the opposite of their effect on exchange rate pass-through. A higher own-price effect leads an exporter to pass-through less of an expected exchange rate change onto import price. However, a higher own-price effect also implies a lower price, so that the percentage change in import price will be higher.

In 4.1 we discuss the effect of expected exchange rate changes on expected and realized profits. We draw connections to the literature on strategic trade policy. ${ }^{10}$ Take the case of an expected choice of what currency to use in trade transactions will be influenced by all three factors. Traditionally trade between developed countries has been denominated in the exporter's currency. For the country where we have access to recent evidence, Sweden, this pattern seems to be changing. Grassman (1973) reported that $66 \%$ of Swedish exports were invoiced in Swedish kronor. By 1995 the share invoiced in kronor had decreased to 44\%. See Friberg and Vredin (1997) for further discussion.

\footnotetext{
${ }^{10}$ See e.g. Brander (1996).
} 
appreciation. Each firm would like to charge a higher price, if only it could make such a "promise" credible (price increases raise profits of both firms in this set-up). An expected appreciation of one exporter's currency allows that firm to credibly commit to a higher price. If the appreciation does not materialize this positive effect from higher prices is the only effect on profits. That is, it would fulfill a role very much like that of an export tax in strategic trade policy.

\section{The model}

There are three countries in the analysis, $x, y$ and $z$. Country $z$ is the single market where goods are sold. The importing firm passes through price changes fully and immediately to consumer prices (alternatively we may think of the foreign firms selling directly to the final users). We focus on a country $x$ firm that faces competition on the $z$ market from a firm from country $y$ (also called the third country). Demand functions are given by:

$$
\begin{aligned}
& q(x)=Q-b p^{*}+\gamma P^{*} \\
& q(y)=Q-b P^{*}+\gamma p^{*}
\end{aligned}
$$

$q(i)$ denotes demand for the product of firm $i=x, y . Q$ is exogenous demand, $p^{*}$ is the price of the good from $x$ and $P^{*}$ is the price of the good from $y$. Both are in terms of the $z$ currency, the currency of importers. Assume that $b, \gamma>0$. The central assumptions are that firms have to set price before exchange rates are known and that consumers choose quantity demanded after the exchange rates are known. Each firm has the choice between setting the export price in his own, in the importers' or in the third country currency. Let $p^{*}$ denote a price that has been set in the importer's currency $(z)$ and $p^{\circ}$ a price that has been set in the country $y$ currency. The super-indexes are also used to denote profits under the different pricing strategies. When pricing in the $x$ currency no super-index is used. The price of the competing firm is taken as given (in the currency in which it is set). We assume that each firm is constrained to produce in his home country. Marginal costs are fixed in each producer's domestic currency and denoted by $c$ for the $x$ firm and $C$ for the $y$ firm. 
Each firm's objective is to maximize expected profits in his home currency.

Let $e$, the stochastic nominal exchange rate denote units of the country $x$ currency needed to buy one unit of the importers' currency, z. A higher value of $e$ thus implies a depreciation of the country $x$ firm's currency relative to currency $z$. Let $e^{o}$ denote units of country $y$ currency needed to buy one unit of the importer's currency. The exchange rate between $x$ and $y$ is given by the relation $e / e^{o}$. Assuming that $e$ and $e^{o}$ are uncorrelated, we can use the property that $E\left(e e^{o}\right)=E(e) E\left(e^{o}\right)$ which greatly simplifies calculations. Implicitly, we assume that exchange rate changes are due to expectations of monetary policy changes in country $x$ and $y$ only and that these are uncorrelated. The analysis is partial equilibrium and exchange rates are exogenous. Let the markup and the support of the exchange rate be such that the ex post markup is always positive. As markups are positive it will be profitable for firms to accommodate ex post demand.

\section{Prices and profits with unchanged expected value of ex- change rates}

In this section we will study expected prices and profits under different choices of price setting currencies. In 3.1 we study the choices of the firm from $x$ when the firm from $y$ sets price in his own currency. In 3.2 we study the choices faced by the firm from $x$ when the firm from $y$ sets price in the importer's currency. Section 3.3 uses expected profits from 3.1 and 3.2 (and expected profits for the case where each firm sets price in the competitor's currency) to analyze the equilibrium choice of price setting currency. Section 3.4 discusses exchange rate exposure, the sensitivity of ex post profits to exchange rate surprises.

\subsection{Third country firm sets price in his own currency}

Let $P, P^{(o)}, P^{(*)}$ denote the price of the competitor from the third country, when the firm from $x$ sets price in his own, country $y$ and country $z$ currency respectively. The maximization problems 
for the $x$ firm are then respectively:

i) pricing in his home currency, $x$ :

$$
\max _{p} E\left[(p-c)\left(Q-\frac{b}{e} p+\frac{\gamma}{e^{o}} P\right)\right]
$$

ii) pricing in the importer's currency, $z$ :

$$
\max _{p^{*}} E\left[\left(e p^{*}-c\right)\left(Q-b p^{*}+\frac{\gamma}{e^{o}} P^{(*)}\right)\right]
$$

iii) pricing in the competitor's, third country currency, $y$ :

$$
\max _{p^{0}} E\left[\left(\frac{e}{e^{o}} p^{o}-c\right)\left(Q-\frac{b}{e^{o}} p^{o}+\frac{\gamma}{e^{o}} P^{(o)}\right)\right]
$$

Solving for the first order conditions of the firm from $x$ yields us the reaction functions. As usual for Bertrand competition they are increasing in the competitor's price when goods are substitutes. Equilibrium prices are found by solving the relevant maximization problem of the competitor ${ }^{11}$ and substituting his optimal price into the home firms first order condition. Solve for the optimal prices for the $x$ firm and denote these by $\hat{p}$. These are given in equations (6)-(8). To shorten notation let $A$ be defined as $A=\frac{2 b}{\left(4 b^{2}-\gamma^{2}\right)}$. We assume that $b>\frac{\gamma}{2}$. That is, the own-price effect on demand is large enough relative to the cross-price effect on demand for prices to be well defined. The equilibrium prices in the respective currencies are then:

i) optimal price in home currency, $x$ :

$$
\widehat{p}=A\left[\left(Q\left(1+\frac{\gamma}{2 b}\right)+\frac{\gamma}{2} C E\left(1 / e^{o}\right)\right) \frac{1}{E(1 / e)}+c b\right]
$$

ii) optimal price in the importer's currency, $z$ :

$$
\widehat{p}^{*}=A\left[Q\left(1+\frac{\gamma}{2 b}\right)+\frac{\gamma}{2} C E\left(1 / e^{o}\right)+\frac{c b}{E(e)}\right]
$$

\footnotetext{
${ }^{11}$ These are given in appendix 1.
} 
iii) optimal price in the competitor's, third country currency, $y$ :

$$
\hat{p}^{o}=A\left[Q\left(\frac{E\left(1 / e^{o}\right)}{E\left(1 /\left(e^{o}\right)^{2}\right)}+\frac{\gamma}{2 b E\left(1 / e^{o}\right)}\right)+\frac{\gamma}{2} C+c b \frac{E\left(1 / e^{o}\right)}{E(e) E\left(1 /\left(e^{o}\right)^{2}\right)}\right]
$$

\subsubsection{Expected prices and profits}

We turn first to expected prices that are faced by the importer and by the exporters. When prices are pre-set expected prices will depend on the price setting currency that is chosen. We use Jensen's inequality and the definition of variance to determine the signs of comparisons. We first study the expected prices to be paid by the importer on imports from $x$

Proposition 1 Expected import price of goods from $x$ is highest when price is set in the $x$ currency and lowest when price is set in the same currency as that of competition, $y: \hat{p} E(1 / e)>\widehat{p}^{*}>$ $\widehat{p}^{o} E\left(1 / e^{o}\right)$

Proof: In appendix 2

The expected price to be paid by the importer is highest when the product is priced in the $x$ currency and lowest when the firms from both countries set price in the third country currency $(y)$. The reverse side of the coin is the expected prices that the country $x$ exporter receives.

Proposition 2 Expected price to be received by the $x$ firm is highest when the $x$ firm sets price in the importer's currency. i)E $(e) \hat{p}^{*}>\widehat{p}$ ii)E $(e) \hat{p}^{*}>E(e) E\left(1 / e^{o}\right) \hat{p}^{o}$ iiii)E(e)E(1/e $\hat{p}^{o}>\hat{p}$ if $\frac{\operatorname{var}\left(1 / e^{o}\right)}{E\left(1 /\left(e^{o}\right)^{2}\right)}$ is sufficiently small.

Proof: In appendix 3

We now focus on the expected price of imports from $y$ that the importer in $z$ meets.

Proposition 3 Expected import price of goods from $y$ is highest when the price of $x$ goods is set in the $x$ currency and lowest when price is set in the $y$ currency: $E\left(1 / e^{o}\right)\left[\widehat{P}>\widehat{P}^{(*)}>\widehat{P}^{(o)}\right]$

Proof: in appendix 4 
The expected prices for imports from $y$ depend on the price setting currency chosen by the country $x$ firm. Expected import prices from $y$ follow the same ordering as do the expected import prices from the $x$ firm. The reason for this being that firms' reaction functions are positive when goods are substitutes. If the $x$ firm charges a higher price it shifts the demand curve outwards for $y$ and it is optimal for the country $y$ firm to raise his price as well. In our model the expected prices that the importer faces are lowest when both firms set price in $y$.

Expressions for expected profits tend to become complicated and hard to sign ${ }^{12}$. We will therefore calculate expected profits under some different parameter values. Table 1 reports some of these results $^{13}$. We study expected profits under two different levels of exchange rate variability. In the calculations the expected value is 1 for both exchange rates. In the case that we call $\mathrm{L}$ (low) there are equal probabilities of a 5 percent depreciation or appreciation. In the case that we call $\mathrm{H}$ (high) there are equal probabilities of a 20 percent depreciation or appreciation. The levels of exchange rate variability were chosen high to highlight the difference in expected profits.

Table 1 about here

We focus on the expected profits for the country $x$ firm. For a wide range of values the highest expected profits for the $x$ firm are reached when he sets price in the importer's currency. The reason for this is analogous to the monopoly case studied by e.g. Baron (1976) and Friberg (1998). When price is set in the importer's currency demand is unaffected by surprises in $e$. Profits will be a linear function of exchange rate surprises in $e$ - expected profits are not affected (this is seen by twice differentiating equation (40) in appendix 5 with respect to $e$ ). If price is set in the $x$ currency, profits are a concave function of exchange rate surprises in $e$ since a demand function that is linear in price then is concave in exchange rate surprises (seen by twice differentiating equation (37) in

\footnotetext{
${ }^{12}$ In Friberg (1996) explicit expressions are calculated and ranked for the case where $\gamma=0$, the monopoly case. Price setting in the importer's currency yields the highest expected profits for a monopolist facing a linear demand function and having constant marginal costs..

${ }^{13}$ In the calculations $Q=6, c=C=1, b=2$.
} 
appendix 5 with respect to $e$ ). Concavity of profits in $e$ imply that the expected value of profits will be affected negatively by the variance of $e$.

The concavity of profits in $e$ can be contrasted to Fischer's (1989, p. 130) discussion of the convexity of the profit function in the price noise. Focus on the simplest case in Fischer's model, one firm from each country. Fluctuating exchange rates and homogenous goods imply that a firm has a positive probability of capturing the whole foreign market, while there is also a probability that he will sell nothing on the foreign market. Profits will be convex in exchange rate fluctuations. In Fischer's model expected profits are increasing in the volatility of the exchange rate. In our model goods are differentiated and quantity is demand determined - the shape of demand and cost functions will determine convexity or concavity of profits in exchange rate fluctuations.

The stronger cross-price effects $(\gamma)$, the more attractive does pricing in currency $y$ become. We can get some intuition for why this could be the case by noting the analog between the issue that we study here and the issue of choosing price or quantity as strategic variable under uncertainty. Klemperer and Meyer (1986) note that the cost of choosing a strategic variable is the cost of deviating from the optimal ex post point on the residual demand curve. The stronger cross-price effects are, the stronger will the effect of surprises in $e^{a}$ be on the ex post demand curve that the $x$ firm faces. A depreciation of the $y$ currency lowers the price of the $y$ good that the importer faces, this shifts the ex post demand curve for $x$ goods downwards. By setting his price in the $y$ currency as well, the $x$ firm will achieve the same adjustment of his price to the importer. ${ }^{14}$ In our model price setting in the $y$ currency yield the highest expected profits only when $\gamma>>b$, when cross-price effects are much stronger than own-price effects. A standard assumption is that own-price effects are stronger than cross-price effects. The example still gives us valuable intuition for why a firm would want to set price in the same currency as competition when cross-price effects are strong.

\footnotetext{
${ }^{14}$ Why shouldn't the $x$ firm always price in the $y$ currency then? Note (equation (43) in appendix 5 ) that demand will be concave in $e^{o}$ through the own-price effect. This tends to lower expected profits.
} 
We also see that the choice of price setting currency by the $x$ firm affects expected profits by the $y$ firm. They are highest when the $x$ firm sets price in his own currency. Higher expected market prices from the $x$ firm allow the $y$ firm to quote a higher optimal price as shown in proposition 3 , the higher expected price resulting in higher expected profits ${ }^{15}$.

\subsection{Third country firm sets price in importer's currency}

We will only briefly study this case. The maximization problems of firms are analogous to those in section 3.1 with straightforward changes of where the exchange rates enter the problem. They are not reported here. In table 2 the expected profits are calculated using the same parameter values as in table 1.

Table 2 about here

We see that when the firm from $x$ prices in the importer's currency expected profits are unaffected by the variance of exchange rates. We also note that expected profits are always highest when the $x$ firm prices in the importer's currency. This is the same result as Baron (1976) found. He showed that, when demand is linear in price and marginal costs are constant (and the residual demand curve unaffected by exchange rate surprises), price setting in the importer's currency maximizes expected profits.

Comparing with table 1 we see that for the $x$ firm it generally led to higher expected profits when the firm from $y$ priced in the $y$ currency. We also note that price setting in his own currency is not optimal for the $y$ firm. ${ }^{16}$ The next section studies the equilibrium choice of price setting currencies.

\footnotetext{
${ }^{15}$ Our results are derived under the assumption that $e$ and $e^{o}$ are uncorrelated. Introducing correlation between the different exchange rates in our model would make it more realistic, but also more complicated. We note for now that the higher the correlation between $e$ and $e^{o}$, the less difference will there be between pricing in an exporter's own currency compared to pricing in the competitors currency. If there is perfect correlation between $e$ and $e^{o}$ expected prices and profits are unaffected by if the $x$ firm sets price in $x$ or in $y$.

${ }^{16}$ Profits when pricing in $y$ do not increase as rapidly as under other pricing practices when $\gamma$ is increased. This is because exchange rate terms enter optimal prices in such a way that price does not "explode“ to the same extent as
} 


\subsection{Equilibrium choice of price setting currencies}

To construct a complete pay-off matrix with expected profits (for the numerical values considered in 3.1 and 3.2) under the possible combinations of price setting currencies we need to calculate expected profits for the case when both firm sets price in the competitor's currency. Using this and expected profits from tables 1 and 2 we construct table 3 which gives the pay-off matrix for the case when the variability of $e$ is $\mathrm{L}$, that of $e^{a}$ is $\mathrm{H}$ and the cross-price effect is 1 . The first number in each box is the expected profits of the firm from $y$ and the second the expected profits of the firm from $x$. For instance the upper left-hand corner says that the expected profit of the firm from $y$ is 5.538 when both firms set price in the $x$ currency. The expected profit of the $x$ firm is then 5.5250 . It is easily verified that it is the dominant strategy for both firms to set price in the importer's currency. We do not report the other pay-off matrixes here since they are easily constructed from tables 1 and 2 (the "missing" case where firms' set price in each others' currencies is always dominated). Price setting in the importer's currency is the dominant strategy for both firms when the strength of cross-price effect, $\gamma$, equals 1 for all the cases that we considered in tables 1 and 2 .

Table 3 about here

As the strength of the cross-price effect is increased to 2 there is no dominant strategy. The only Nash equilibrium is however for both firms to set price in the importer's currency (the same holds for the case when $\gamma=3$ ). For the unlikely case that $\gamma=3.9$ we have three Nash equilibria, for both firms to set price in $x$, both firms pricing in $z$ and both firms pricing in $y$.

\subsection{Exchange rate exposure}

Exchange rate exposure is defined as the current expectation of the sensitivity of the value of the firm to future exchange rate surprises ${ }^{17}$. The price setting currencies of both firms' will affect how under the other price setting currencies when $\gamma$ is increased. We have no intuition for this result at present.

${ }^{17}$ Adler and Dumas (1984). 
the $x$ firm is affected by exchange rate surprises. The exchange rate exposure of the $x$ firm is given by

$$
d \pi\left(\widehat{p}, e, e^{o}\right)=\frac{\partial \pi\left(\widehat{p}, e, e^{o}\right)}{\partial e} d e+\frac{\partial \pi\left(\widehat{p}, e, e^{o}\right)}{\partial e^{o}} d e^{o}
$$

This section studies the exchange rate exposure of the $x$ firm both for the case when the competitor sets price in his own currency (section 3.4.1) and when the competitor sets price in the importer's currency, (section 3.4.2).

\subsubsection{Third country firm sets price in his own currency}

Appendix 5 reports expressions for the partial derivatives of the $x$ firm's profit function with respect to exchange rates when the $y$ competitor sets price in his own currency $(y)$. Here it should be noted that demand is uncertain no matter what currency the $x$ firm sets prices in. A surprise depreciation of the $x$ firm's home currency against currency $z$, (a higher value of $e$ ), has a positive effect on the $x$ firm's profits no matter what currency that prices are set in.

When the $x$ firm sets price in the competitor's currency, the effects on the $x$ firm's profits from a depreciation of the $y$ currency stem both from price and demand effects. The price that the $x$ firm receives is lower. Demand is affected positively by the lower price that customers meet on the $x$ firm's goods and negatively by the lower price of the competitor's good.

Another property of the framework that follows from the assumption of competition based in a third country may be worth noting. The response of a corporate cash flow, to a depreciation of the $x$ currency relative to that of the firm's market, is dependent on if it is $x$ that depreciates, or if it is $z$ that appreciates against both the other currencies. The effects are clearly larger in the first case - in that case our goods not only become cheaper in the foreign market, they also become cheaper relative to the competition. If the importer's currency appreciates against both the other currencies our goods become cheaper, but so do the goods of our foreign competitor. The largest boost to an exporter's profits is of course given if his own currency depreciates relative to the market and the competitor's currency appreciates against that of the market. 


\subsubsection{Third country firm sets price in the importer's currency}

We will focus on the exchange rate exposure of the $x$ firm when he sets price in the importer's currency as well. The realized ex post profits of the $x$ firm are then given by

$$
\pi^{*}=\left(e \widehat{p}^{*}-c\right)\left(Q-b \widehat{p}^{*}+\gamma \widehat{P}^{*}\right)
$$

We note that the exchange rate exposure in this case is simply given by (the certain) revenues

in foreign currency. $\left(\frac{\partial \pi^{*}}{\partial e}=\widehat{p}^{*}\left(Q-b \widehat{p}^{*}+\gamma \widehat{P}^{*}\right) ; \frac{\partial \pi^{*}}{\partial e^{o}}=0\right)$. Demand is unaffected by exchange rate surprises, the only uncertainty concerns the exchange rate at which the $x$ firm will translate its foreign revenue into domestic currency. The exchange rate exposure of the firm will be the equivalent of the transaction exposure ${ }^{18}$.

Now for a moment interpret price setting in the importer's currency to simply mean that firms tend to keep import prices stable in the importer's currency. This then means that pricing-tomarket/less than full exchange rate pass-through tends to limit exchange rate exposure to transaction exposure. Demand elasticities, strength and origin of competition and other market structure variables will be of little importance for the exchange rate exposure of a firm if all firms keep import prices stable. This relationship between price stability in the importer's currency and exchange rate exposure stresses the role of exchange rate pass-through for exchange rate exposure. Our discussion may give some intuition for why many firms seem to focus so much on the management of transaction exposure as opposed to the resources that they devote to the management of total economic exposure to exchange rates ${ }^{19}$ (which incorporates competitive effects, see e.g. Sercu and Uppal,

\footnotetext{
${ }^{18}$ Transaction exposure arises on assets that are denominated in foreign currency and whose value in the exporter's currency is uncertain. See e.g. Sercu and Uppal (1995). It normally relates to past contractual undertakings, but, just as in our case, it measures the exposure of a certain foreign currency revenue.

Marston (1996) in his study of quantity competition under exchange rate uncertainty makes a similar finding - that under many forms of quantity competition the exchange rate exposure is simply proportional to revenues in foreign currency. That result is driven by the envelope theorem, quantities are determined by the exchange rate - by the first order condition for profit maximization the effect of a change in quantity on profit is $\mathbf{0}$.

${ }^{19}$ See e.g. Belk and Glaum (1990).
} 
$1995)$.

\section{Changes in expected exchange rates}

We will now study the behavior of prices and profits when the expected value of exchange rates change. The theoretical literature on exchange rate-pass through has found the degree of passthrough to depend on how the demand elasticity changes along the demand curve (i.e. the curvature of the demand curve). If the demand elasticity increases as the price rises there will be incomplete pass-through. There has been little study of price competition with differentiated goods ${ }^{20}$, uncertainty ${ }^{21}$ or competition from third countries. Attention to how industry characteristics influences pass-through has focused on concentration ratios and the relative numbers of competitors from different countries.

In our simple framework we investigate how the strength of own-price and cross-price effects affect pass-through. We stress the distinction between how own- and crossprice effects affect passthrough $\left(\frac{d \widehat{p}^{*}}{d E(e)}\right)$ vs. how they affect the pass-through elasticity $\left(\frac{d \widehat{p}^{*}}{d E(e)} \frac{E(e)}{\widehat{p}^{*}}\right)$. The distinction is important as much of the empirical work on exchange rate pass-through (surveyed in Menon 1995) studies pass-through elasticities, whereas discussions and hypotheses about how market structure and market power affect pass-through behavior often relate to pass-through.

To keep the issue as simple as possible assume in this section that both firms set price in the importer's currency (which also was the dominant strategy for the most realistic cases in 3.3). This means that pass-through measures the actual price change in response to an expected exchange rate

\footnotetext{
${ }^{20}$ Feenstra, Gagnon and Knetter (1996) and Baniak and Phlips (1995) are two exceptions.

${ }^{21}$ Fischer (1989) is the only exception. Some papers, e.g. Feenstra (1989), include uncertainty but study a certainty equivalent structure and carry out the analysis under the assumption that the ex post realised exchange rate is equal to the ex ante expected exchange rate. Feenstra and Kendall (1997) introduce risk aversion, forward markets and study price setting in both the importer's and exporter's currency. The focus is quite different from the present paper. Their model predicts that firms' hedging should lead to PPP holding on forward rather than spot exchange rates.
} 
change $^{22}$. The $x$ firm's maximization problem is given by

$$
\max _{p^{*}} E\left[\left(e p^{*}-c\right)\left(Q-b p^{*}+\gamma P^{*}\right)\right]
$$

and that of the country $y$ firm by

$$
\max _{P^{*}} E\left[\left(e^{o} P^{*}-C\right)\left(Q-b P^{*}+\gamma p^{*}\right)\right]
$$

The corresponding first order conditions are given by

$$
\begin{aligned}
E(e) Q-E(e) 2 b p^{*}+\gamma E(e) P^{*}+c b & =0 \\
E\left(e^{o}\right) Q-E\left(e^{o}\right) 2 b P^{*}+\gamma E\left(e^{o}\right) p^{*}+C b & =0
\end{aligned}
$$

Totally differentiate (14) and (13), let $d E\left(e^{o}\right)=0$ to solve for pass-through (alternatively solve for the equilibrium price and differentiate this with respect to $E(e)$.

Proposition 4 Exchange rate pass-through, $\left.\frac{d \widehat{p}^{*}}{d E(e)}\right|_{d E\left(e^{o}\right)=0}$, is always negative. The absolute value of the pass-through is decreasing in the own-price effect, increasing in the cross-price effect and decreasing in the variance of the exchange rate when the exchange rate is distributed log-normally with mean $\mu$ and standard deviation $\sigma$.

Proof: Pass-through is given by

$$
\left.\frac{d \widehat{p}^{*}}{d E(e)}\right|_{d E\left(e^{o}\right)=0}=\frac{\partial \widehat{p}^{*}}{\partial E(e)}=-\frac{2 b^{2} c}{\left(4 b^{2}-\gamma^{2}\right) E(e)^{2}}<0
$$

All terms in (15) are positive which establishes that pass-through is negative. Define $P T \equiv\left|\frac{\partial \widehat{p}^{*}}{\partial E(e)}\right|$. The absolute value of pass-through is decreasing in $b$ since

$$
\operatorname{sign}\left(\frac{\partial P T}{\partial b}\right)=\operatorname{sign}\left(-4 b c \gamma^{2} E(e)^{2}\right)<0
$$

\footnotetext{
${ }^{22}$ Note that pass-through here is differently defined than what is usually the case. We study the change in import prices due to a depreciation of the exporter's currency. This is negative, a depreciation leads the exporter to lower his price to consumers. Often pass-through is defined as the percentage change in import prices due to a percentage depreciation of the importers currency (1/e in or model) in which case it is positive.
} 
and increasing in cross-price effects since

$$
\frac{\partial P T}{\partial \gamma}=\frac{2 b^{2} c}{\left(4 b^{2}-\gamma^{2}\right)^{2} E(e)^{2}} 2 \gamma>0
$$

$P T$ is decreasing in the volatility of the exchange rate when $e$ is distributed log-normally with mean $\mu$ and standard deviation $\sigma$, since

$$
\frac{\partial P T}{\partial \sigma^{2}}=-\frac{4 b^{2} c \sigma}{\left(4 b^{2}-\gamma^{2}\right)\left(\exp \left(\mu+\frac{1}{2} \sigma^{2}\right)\right)^{2}}<0
$$

A firm that has lower mark-ups (higher $b$, lower $\gamma$ ) passes through less of the expected exchange rate change (that is, the absolute value of pass-through is lower). The more that demand decreases when a firm raises its price, the less does a firm want to pass through an exchange rate change. That an increase in the noisiness of the exchange rate leads to less response of the pre-set price is also intuitively appealing. The worse the quality of the signal (higher variance of the exchange rate), the less will the pre-set price respond to the signal. This could be one way in which lower exchange rate variability could improve the effectiveness of the "price signal".

We now turn to a discussion of exchange rate pass-through elasticities, the issue is important as most of the empirical work in the area studies pass-through elasticities and not pass-through itself. Effects on the equilibrium pass-through elasticity of changing $b$ and $\gamma$ are then the opposite of the effect of changing those parameters on pass-through.

Proposition 5 The exchange rate pass-through elasticity, $\frac{\partial \widehat{p}^{*}}{\partial E(e)} \frac{E(e)}{\widehat{p}^{*}}$, is always negative and less than unity in absolute value. The absolute value of the pass-through elasticity is decreasing in the cross-price effect, increasing in the own-price effect and decreasing in the variance of the exchange rate process when the exchange rate is distributed log-normally with mean $\mu$ and standard deviation $\sigma$.

Proof: The pass-through elasticity is given by

$$
\frac{\partial \widehat{p}^{*}}{\partial E(e)} \frac{E(e)}{\widehat{p}^{*}}=-\frac{c b}{E(e)\left(Q\left(1+\frac{\gamma}{2 b}\right)+\frac{\gamma}{2 E\left(e^{\circ}\right)} C\right)+c b}<0
$$


All terms in (19) are positive which establishes that the pass-through elasticity is negative. It is also immediately clear from (19) that the pass-through elasticity will be between 0 and -1 . Define $\theta=\left|\frac{\partial \hat{p}^{*}}{\partial E(e)} \frac{E(e)}{\hat{p}^{*}}\right|$ and $G=Q\left(1+\frac{\gamma}{2 b}\right)+\frac{\gamma}{2 E\left(e^{\circ}\right)} C$. The absolute value of the pass-through elasticity is increasing in $b$ since

$$
\frac{\partial \theta}{\partial b}=\frac{c\left(E(e) Q\left(1+\frac{\gamma}{b}\right)+\frac{\gamma}{2} \frac{C}{E\left(e^{o}\right)}\right)}{(E(e) G+c b)^{2}}>0
$$

and decreasing in $\gamma$ since

$$
\frac{\partial \theta}{\partial \gamma}=-\frac{c b}{(E(e) G+c b)^{2}}\left(\frac{Q}{2 b}+\frac{C}{2 E\left(e^{o}\right)}\right) E(e)<0
$$

$\theta$ is decreasing in the volatility of the exchange rate, when $e$ is distributed log-normally with mean $\mu$ and standard deviation $\sigma$, since

$$
\frac{\partial \theta}{\partial \sigma^{2}}=-\frac{c b}{\left(\exp \left(\mu+\frac{\sigma^{2}}{2}\right) G+c b\right)^{2}} G \sigma \exp \left(\mu+\frac{\sigma^{2}}{2}\right)<0
$$

The simplest way to understand what the difference in pass-through and pass-through elasticities stems from is to discuss the effects of increasing $b$, the own-price effect. The change in import price, due to an expected exchange rate change, is larger the lower $b$ is (as showed in proposition 4). But a lower $b$ implies a higher price so that the percentage change in import price, due to a percentage change in the expected exchange rate, is lower the lower $b$ is. A particular case in point is the case where $\gamma=0$, monopoly. It is then well known that pass-through then is independent of $b$ (see e.g. Feenstra, Gagnon and Knetter 1996). Since the change in import price is not dependent on $b$, but the level of the price itself is (lower $b$ implies a higher price), the percentage change in import price will be dependent on $b$.

In the analysis above we have kept $d E\left(e^{o}\right)=0$. We should also note however that more generally the price that the country $x$ firm charges is affected not only by the expected exchange rate between currency $x$ and the importer's currency, but also by the exchange rate between the importer's currency and the country $y$ currency. $\frac{\partial \hat{p}^{*}}{\partial E\left(e^{o}\right)}=-A\left(\frac{\gamma}{2 E\left(e^{\circ}\right)^{2}} C\right)<0$. If the $y$ currency is expected to depreciate the $x$ firm exporter will decrease his price. An expected depreciation of the $y$ firm's 
home currency leads him to charge a lower price on the $z$ market - it is then optimal for the firm from $x$ to lower his price as well.

\subsection{Effect on profits from an expected depreciation}

Solving for the optimal prices from (13) and (14) and plugging them into the respective maximization problems gives the expected profits of the two competitors.

$$
\begin{aligned}
& E\left(\pi^{*}\right)=\left(E(e) \hat{p}^{*}-c\right)\left(Q-b \widehat{p}^{*}+\gamma \widehat{P}^{*}\right) \\
& E\left(\Pi^{*}\right)=\left(E\left(e^{o}\right) \widehat{P}^{*}-C\right)\left(Q-b \widehat{P}^{*}+\gamma \widehat{p}^{*}\right)
\end{aligned}
$$

To shorten notation define $\widehat{q}(x) \equiv\left(Q-b \widehat{p}^{*}+\gamma \widehat{P}^{*}\right)$. Totally differentiating expected profits yields

$$
d E\left(\pi^{*}\right)=\widehat{p}^{*} \widehat{q}(x) d E(e)+\frac{\partial E\left(\pi^{*}\right)}{\partial p^{*}} d p^{*}+\frac{\partial E\left(\pi^{*}\right)}{\partial P^{*}} d P^{*}+\frac{\partial E\left(\pi^{*}\right)}{\partial E\left(e^{o}\right)} d E\left(e^{o}\right)
$$

Use first order conditions (13) and (14), let $d E\left(e^{o}\right)=0$, to express (25) as

$$
\frac{d E\left(\pi^{*}\right)}{d E(e)}=\hat{p}^{*} \widehat{q}(x)-\left(E(e) \hat{p}^{*}-c\right) \gamma A\left(\frac{\gamma}{2 E(e)^{2}} c\right)
$$

The first term is positive, a depreciation of the country $x$ currency will make the $x$ firm's total foreign currency revenues more worth in its own currency. The second effect is negative, an expected depreciation lowers the price that competition charges. This leads to lower demand for the country $x$ exporter's goods which lowers profits. The first order condition, (13), implies that the direct effect on expected profits from changing his own price is 0 for the firm from $x$. There is thus no direct effect on expected profits from the lower price charged by the country $x$ firm. We depict firms' reaction functions in figure 1 below. An expected depreciation of the $x$ currency shifts the $x$ firm's reaction function inwards, both firms lower their prices.

figure 1 about here

We also note another implication of (26) - an expected depreciation that does not materialize affects realized profits negatively. The expected depreciation lowers the prices of both firms as in 
figure 1 which leads to lower profits. In the case where the depreciation does not happen this will be the only effect on realized profits (for small surprises the only effect on profits will be through the lower price that competition charges, for larger surprises there will also be a negative effect on profits from the lower price that the $x$ firm himself charges, $\frac{\partial \pi^{*}}{\partial p^{*}}=0$ will then not hold). We have what might be called a "problem due to a Peso problem"23. We also note that an expected appreciation that does not materialize benefits both firms. The intuition being the same as that behind the result that the optimal strategic trade policy under Bertrand competition is an export $\operatorname{tax}^{24}$. The firm from $x$ would like to charge a higher price than the Bertrand level, if only it could commit to it. An export tax makes the higher price credible. Here an expected appreciation serves the same role. In the case where the appreciation does happen, the positive effect on profits for the $x$ firm is outweighed by the negative translation effect.

\section{Conclusions}

Even though the model presented in this paper relies on a very simple structure it allowed us to study issues that have received little attention previously.. Choice of price setting currency when there is competition from a third country, connections between price setting currencies and economic exposure, and effects of expected exchange rate changes on profits. We demonstrated the attractiveness of setting price in the importer's currency for both firms. That pricing in the same currency as competition becomes more attractive the stronger cross-price effects are may help explain behavior such as the invoicing patterns shown by Swedish forestry firm Södra Skogsägarna. Exports of softwood pulp to European countries is invoiced in dollars. The majority of competition in softwood pulp is based in North America. Hardwood pulp on the other hand is invoiced in

\footnotetext{
${ }^{23}$ A Peso problem normally relates to a future discrete shift in policy that does not materialize during the period studied. The expected value of the exchange rate may therefore be different from the observed average value over a long period. See e.g. Lewis (1996).

${ }^{24}$ See e.g. Brander (1996).
} 
Ecu and the majority of competition comes from Spain and Portugal. The choice of price setting and invoicing currency thus seems ruled by concerns as to the competitive structure rather than medium-of-exchange or store-of-value roles of currency.

We have also stressed that depending on if we study pass-through or the pass-through elasticity, we should expect different effects from market power and substitutability. The effect of substitutability on pass-through elasticities is the opposite in our Bertrand framework than what is hypothesized in e.g. Menon (1996). This stresses the need for formal models underlying empirical studies of pass-through - we should not expect structural variables to have the same effect on pass-through irrespective of the form of competition. Under the assumption that the exchange rate is distributed log-normally we showed that pass-through was lower the more volatile the exchange rate was. This is a result of the same flavor as Krugman's $(1989$, p.54) finding (in a "sunk cost" model) that, "the exchange rate has so little effect in part because it fluctuates so much".

Finally, as discussed in the introduction, it is surprising that there has been so little study of price competition under exchange rate uncertainty - there are many ways in which it should be fruitful to extend the present work. One extension is to include several competitors and study how the country distribution of competitors affects pass-through. Extending the analysis to include two markets would enable us to discuss Pricing-to-Market issues. Using more general functional forms and allowing for futures markets and risk aversion are examples of extensions that should be interesting, though at a price of probably making analysis more involved.

\section{References}

[1] Adler, M. and Dumas, B. (1984). Exposure to currency risk: definition and measurement, Financial Management, vol. 13, pp. 41-50.

[2] Baniak, A. and Phlips L. (1995). La Pléiade and exchange rate pass-through, International Journal of Industrial Organization, vol. 13, pp. 195-211. 
[3] Baron, D. (1976). Fluctuating exchange rates and the pricing of exports, Economic Inquiry, vol. 14 , pp. $425-438$.

[4] Belk, B. and Glaum M. (1990). The management of foreign exchange risk in UK multinationals, an empirical investigation, Accounting and Business Research, vol. 21, pp. 3-13.

[5] Brander, J. (1996). Strategic trade policy, in: Grossman, G. and Rogoff, K. eds., Handbook of International Economics Vol. III, (Elsevier, Amsterdam), pp. 1395-1455.

[6] Dornbusch, R., 1987, Exchange rates and prices, The American Economic Review, vol. 77, pp. $93-106$.

[7] Feenstra, R. (1989). Symmetric pass-through of tariffs and exchange rates: an empirical test, Journal of International Economics, vol. 27, pp. 25-45.

[8] Feenstra, R., Gagnon J. and Knetter, M. (1996). Market share and exchange rate pass-through in world automobile trade, Journal of International Economics, vol. 40, pp. 187-207.

[9] Feenstra, R. and J. Kendall (1997), Pass-through of exchange rates and purchasing power parity, Journal of International Economics 43, 237-261.

[10] Fischer, E. (1989). A model of exchange rate pass-through, Journal of International Economics, vol. 26, pp. 119-137.

[11] Friberg, R. (1996). On the role of pricing exports in a third currency, Working Paper Series in Economics and Finance No. 128 (Stockholm School of Economics).

[12] Friberg, R. and A. Vredin (1997), Exchange rate uncertainty and the microeconomic benefits from EMU, forthcoming, Swedish Economic Policy Review.

[13] Friberg, R. (1998). In which currency should exporters set their prices?, forthcoming, Journal of International Economics. 
[14] Gottfries, N. (1994). Market shares, financial constraints, and pricing behavior in the export industry, Seminar paper no 586, Institute for International Economic Studies, Stockholm.

[15] Klemperer, P. and Meyer, M. (1986). Price competition vs. quantity competition: the role of uncertainty, Rand Journal of Economics, vol. 17, pp. 618-638.

[16] Krugman, P. (1987). Pricing to market when the exchange rate changes, in: S. Arndt and Richardson D. eds., Real-Financial Linkages among Open Economies, (MIT Press, Ma), pp. $49-70$.

[17] Krugman, P. (1989). Exchange-rate instability, (MIT Press, Ma).

[18] Lewis, K. (1996). Puzzles in international financial markets, in: G. Grossman and Rogoff, K. eds., Handbook of International Economics Vol. III, (Elsevier, Amsterdam), pp. 1913-1971.

[19] Luehrman, T. (1990). The exchange rate exposure of a global competitor, Journal of International Business Studies, pp. 225-242.

[20] Marston, R. (1996). The effects of industry structure on economic exposure, NBER Working Paper \#5518.

[21] Menon, J. (1995). Exchange rate pass-through, Journal of Economic Surveys 9, 197-231.

[22] Menon, J. (1996). The degree and determinants of exchange rate pass-through: market structure, non-tariff barriers and multinational corporations, The Economic Journal, vol. 106, pp. 434-444.

[23] Owen, R., and Perrakis, S. (1988). An international duopoly model under exchange rate uncertainty, Révue Économique, vol. 5, pp. 1035-1060.

[24] Sercu, P. and Uppal, R. (1995). International financial markets and the firm, (Chapman \& Hall, London).

\section{Appendix 1}


Maximization problems of the foreign competitor (country $y$ firm), when the country $x$ firm sets its price in currency $x, z$ and $y$ respectively.

$$
\begin{gathered}
\max _{P} E\left[(P-C)\left(Q-\frac{b}{e^{o}} P+\frac{\gamma}{e} p\right)\right] \\
\max _{P^{(*)}} E\left[\left(P^{(*)}-C\right)\left(Q-\frac{b}{e^{o}} P^{(*)}+\gamma p^{*}\right)\right] \\
\max _{P^{(o)}} E\left[\left(P^{(o)}-C\right)\left(Q-\frac{b}{e^{o}} P^{(o)}+\frac{\gamma}{e^{o}} p^{o}\right)\right]
\end{gathered}
$$

\section{Appendix 2}

Comparison of expected prices for imports from $x$.

i) compare $\widehat{p} E(1 / e)$ and $\widehat{p}^{*}$

$$
\hat{p} E(1 / e)-\widehat{p}^{*}=A c b\left(E(1 / e)-\frac{1}{E(e)}\right)
$$

Jensen's inequality implies that the second term is positive $\Rightarrow \widehat{p} E(1 / e)>\hat{p}^{*}$.

ii) Compare $\hat{p}^{o} E\left(1 / e^{o}\right)$ and $\hat{p}^{*}$

$$
\widehat{p}^{o} E\left(1 / e^{o}\right)-\widehat{p}^{*}=\left(\frac{E\left(1 / e^{o}\right)^{2}}{E\left(1 /\left(e^{o}\right)^{2}\right)}-1\right)\left(Q+\frac{c b}{E(e)}\right)
$$

Using the definition of variance, $\operatorname{var}(x)=E\left(x^{2}\right)-E(x)^{2}$, we write this is as $-\frac{\operatorname{var}\left(1 / e^{o}\right)}{E\left(1 /\left(e^{o}\right)^{2}\right)}\left(Q+\frac{c b}{E(e)}\right)<$ 0 . This establishes proposition 1.

\section{Appendix 3}

Comparison of expected prices to be received by the country $x$ exporter.

i) Compare $\widehat{p}$ and $\widehat{p}^{*} E(e)$.

$$
\widehat{p}-\widehat{p}^{*} E(e)=A\left(\frac{1}{E(1 / e)}-E(e)\right)\left(Q\left(1+\frac{\gamma}{2 b}\right)+\frac{\gamma}{2} C E\left(1 / e^{o}\right)\right)
$$

Jensen's inequality $\Rightarrow \widehat{p}-\widehat{p}^{*} E(e)<0$.

ii) Compare $E(e) E\left(1 / e^{o}\right) \hat{p}^{o}$ and $E(e) \hat{p}^{*}$.

$$
E(e) E\left(1 / e^{o}\right) \hat{p}^{o}-E(e) \hat{p}^{*}=-E(e) A \frac{\operatorname{var}\left(1 / e^{o}\right)}{E\left(1 /\left(e^{o}\right)^{2}\right)}\left(Q+\frac{c b}{E(e)}\right)<0 .
$$


iii) Compare $E(e) E\left(1 / e^{o}\right) \hat{p}^{o}$ and $\hat{p}$.

$$
E(e) E\left(1 / e^{o}\right) \hat{p}^{o}-\hat{p}=\left(E(e)-\frac{1}{E(1 / e)}\right) Q\left(1+\frac{\gamma}{2 b}\right)-\frac{\operatorname{var}\left(1 / e^{o}\right)}{E\left(1 /\left(e^{o}\right)^{2}\right)}(E(e) Q+c b)
$$

Jensen's inequality implies that the first term is positive. The second is negative. For high enough variance in $e^{o}$ the whole expression will be negative. This establishes proposition 2 .

\section{Appendix 4:}

Optimal equilibrium price for the firm from $y$ are found by using the first order conditions from (3)-(5) into the first order conditions from appendix 1.

i) Compare $\widehat{P}$ and $\widehat{P}^{(*)}$.

$$
\widehat{P}-\widehat{P}^{(*)}=\frac{b \gamma}{\left(4 b^{2}-\gamma^{2}\right) E\left(1 / e^{o}\right)} c\left(E(1 / e)-\frac{1}{E(e)}\right)
$$

Jensen's inequality $\Rightarrow \widehat{P}>\widehat{P}^{(*)}$

ii) Compare $\widehat{P}^{(o)}$ and $\widehat{P}$.

$$
\widehat{P}^{(o)}-\widehat{P}^{(*)}=-\frac{b \gamma}{\left(4 b^{2}-\gamma^{2}\right) E\left(1 / e^{o}\right)}(Q+c b) \frac{\operatorname{var}\left(1 / e^{o}\right)}{E\left(1 /\left(e^{o}\right)^{2}\right)}
$$

We see that $\widehat{P}>\widehat{P}^{(*)}>\widehat{P}^{o}$. This establishes proposition 3 .

\section{Appendix 5}

i) Price set in the home currency, $x$ :

$$
\begin{aligned}
\pi & =(\widehat{p}-c)\left(Q-\frac{b}{e} \widehat{p}+\frac{\gamma}{e^{o}} \widehat{P}\right) \\
\frac{\partial \pi}{\partial e} & =(\widehat{p}-c) \frac{b}{e^{2}} \widehat{p}>0 \\
\frac{\partial \pi}{\partial e^{o}} & =-(\widehat{p}-c) \frac{\gamma}{e^{o 2}} \widehat{P}<0
\end{aligned}
$$

ii) Price set in the importers' currency, z

$$
\begin{aligned}
\pi^{*} & =\left(e \widehat{p}^{*}-c\right)\left(Q-b \widehat{p}^{*}+\frac{\gamma}{e^{o}} \widehat{P}^{(*)}\right) \\
\frac{\partial \pi^{*}}{\partial e} & =\widehat{p}^{*}\left(Q-b \widehat{p}^{*}+\frac{\gamma}{e^{o}} \widehat{P}^{(*)}\right)>0 \\
\frac{\partial \pi^{*}}{\partial e^{o}} & =-\left(e \widehat{p}^{*}-c\right) \frac{\gamma}{e^{o 2}} \widehat{P}^{(*)}<0
\end{aligned}
$$


iii) Price set in the competitor's currency, $y$

$$
\begin{aligned}
\pi^{o} & =\left(\frac{e}{e^{o}} \hat{p}^{o}-c\right)\left(Q-\frac{b}{e^{o}} \hat{p}^{o}+\frac{\gamma}{e^{o}} \widehat{P}^{(o)}\right) \\
\frac{\partial \pi^{o}}{\partial e} & =\frac{\hat{p}^{o}}{e^{o}}\left(Q-\frac{b}{e^{o}} \hat{p}^{o}+\frac{\gamma}{e^{o}} \widehat{P}^{(o)}\right)>0 \\
\frac{\partial \pi^{o}}{\partial e^{o}} & =-\frac{e}{e^{o 2}} \hat{p}^{o}\left(Q-\frac{b}{e^{o}} \widehat{p}^{o}+\frac{\gamma}{e^{o}} \widehat{P}^{(o)}\right)+\frac{1}{e^{o 2}}\left(\frac{e}{e^{o}} \hat{p}^{o}-c\right)\left(b \hat{p}^{o}-\gamma \widehat{P}^{(o)}\right)
\end{aligned}
$$

